\title{
First report of the zoonotic nematode Baylisascaris procyonis in non-native raccoons (Procyon lotor) from Italy
}

\author{
Andrea Lombardo ${ }^{1}$, Giuseppina Brocherel ${ }^{1}$, Carla Donnini ${ }^{1}$, Gianluca Fichi ${ }^{2}$, Alessia Mariacher ${ }^{2 *}$ (D) \\ , Elena Lavinia Diaconu ${ }^{3}$, Virginia Carfora ${ }^{3}$, Antonio Battisti ${ }^{3}$, Nadia Cappai ${ }^{4}$, Luca Mattioli ${ }^{5}$ and \\ Claudio De Liberato ${ }^{3}$
}

\begin{abstract}
Baylisascaris procyonis is a nematode parasite of the raccoon (Procyon lotor), and it can be responsible for a severe form of larva migrans in humans. This parasite has been reported from many countries all over the world, after translocation of its natural host outside its native geographic range, North America. In the period between January and August 2021, 21 raccoons were cage-trapped and euthanized in Tuscany (Central Italy), in the context of a plan aimed at eradicating a reproductive population of this non-native species. All the animals were submitted for necroscopic examination. Adult ascariids were found in the small intestine of seven raccoons (prevalence 33.3\%). Parasites have been identified as B. procyonis based on both morphometric and molecular approaches. The aim of the present article is to report the first finding of this zoonotic parasite from Italy, highlighting the sanitary risks linked to the introduction of alien vertebrate species in new areas.
\end{abstract}

Keywords: Baylisascaris procyonis, Italy, Larva migrans, Procyon lotor, Raccoon

Baylisascaris procyonis is an ascariid nematode parasite of the raccoon, Procyon lotor. In the native range of its host, North America, its prevalence can be very high, at times exceeding $70 \%[1,2]$. Baylisascaris procyonis has a direct life cycle, following the fecal-oral route. An infected raccoon can shed each day millions of B. procyonis eggs, which can remain infective in the environment for years, leading to long-lasting contamination of the habitat [3]. Moreover, many species of paratenic hosts, both birds and mammals, can acquire the infection by ingesting the eggs shed in the environment, the same being for humans [2]. In paratenic hosts, B. procyonis larvae migrate to several tissues, including lungs and

*Correspondence: alessia.mariacher@izslt.it

${ }^{2}$ Istituto Zooprofilattico Sperimentale del Lazio e Della Toscana "M Aleandri", Grosseto, Italy

Full list of author information is available at the end of the article abdominal viscera (visceral larva migrans, VLM), eye (ocular larva migrans, OLM), and central nervous system (neural larva migrans, NLM), representing a source of infection for raccoons feeding on the paratenic hosts [1]. In human patients, B. procyonis larvae are not markedly neurotropic, since a relatively low percentage of larvae actually reach the central nervous system (CNS) [4]. Therefore, infections sustained by a low number of larvae may only elicit seroconversion with subtle CNS disease. Nevertheless, when a higher burden of infective eggs is ingested, massive larval migration can result in CNS colonization, with a very severe or even fatal condition. Most NLM cases in humans involve children, due to pica and poor hygienic behavior $[1,4,5]$.

Following the introduction of the raccoon in many European countries, since the 1830s [2] B. procyonis has progressively increased its geographical range. At present, this parasite has been reported in non-native original author(s) and the source, provide a link to the Creative Commons licence, and indicate if changes were made. The images or other third party material in this article are included in the article's Creative Commons licence, unless indicated otherwise in a credit line to the material. If material is not included in the article's Creative Commons licence and your intended use is not permitted by statutory regulation or exceeds the permitted use, you will need to obtain permission directly from the copyright holder. To view a copy of this licence, visit http://creativecommons.org/licenses/by/4.0/. The Creative Commons Public Domain Dedication waiver (http://creativeco mmons.org/publicdomain/zero/1.0/) applies to the data made available in this article, unless otherwise stated in a credit line to the data. 
raccoon populations from Denmark [6], Austria [7], Poland [8], and Germany [9], where some human infections have been described as well $[10,11]$. In Italy, the raccoon was first reported in 2004 in Lombardy, Northern Italy [12]. Nowadays, this species is also present with a reproducing population in Tuscany, Central Italy [13], within the Casentino valley territory. The Casentino valley encompasses the river basin of the upper Arno, within the province of Arezzo, and is characterized by woodlands and hills, interspersed with high-yield crops such as vineyards, fruit trees, white spruce, and black pine. The origin of the raccoon population in Casentino is still debated, but it can probably be traced back to accidental escapes from captivity in the early 2000s. Raccoons have rapidly expanded in the Casentino valley, and some animals have been recently sighted near the Emilia-Romagna border. Due to the invasive nature of the raccoon, and to the environmental and health issues linked to its presence, the Italian authorities set up an eradication plan [14], with the aim of removing raccoon populations in accordance with Regulation (EU) 1143/2014.

The aim of the present article is to describe the first report of B. procyonis from non-native raccoons in Italy, emphasizing the sanitary risks linked to the introduction of this species in new areas.
Between January and August 2021, 21 free-ranging adult raccoons (13 males and eight females, weight $4.3 \pm 1.9 \mathrm{~kg}$ ) from the Casentino valley, Arezzo, Tuscany (Central Italy), were cage-trapped in four different sites (Fig. 1) and euthanized in the context of a state-instituted eradication plan. Euthanasia was performed by trained personnel of the local police authority, by shooting with a free bullet, according to Reg. 2010/63/EU Annex IV guidelines for "other carnivores." Trapping, handling, and euthanasia procedures were performed in order to minimize pain, suffering, distress, or lasting harm. The animals were submitted to the authors' institution for necropsy. In April 2021, on examination of the alimentary tract, one individual was found to harbor ascariid nematodes in the small intestine. After this first finding, six other raccoons were found to harbor these parasites (from one to over 100 adult specimens). In two of the infected raccoons, a partial intestinal obstruction was observed, caused by the high burden of adult parasites (over 100 specimens). Both male and female parasites were recovered. No other parasite species were recovered from the examined animals. The range of parasite burden for each positive raccoon is shown in Table 1.

Morphometric features were consistent with those of B. procyonis as reported by previous studies (Table 2): length 9-16 cm, width $1-3 \mathrm{~mm}$, white-yellowish to

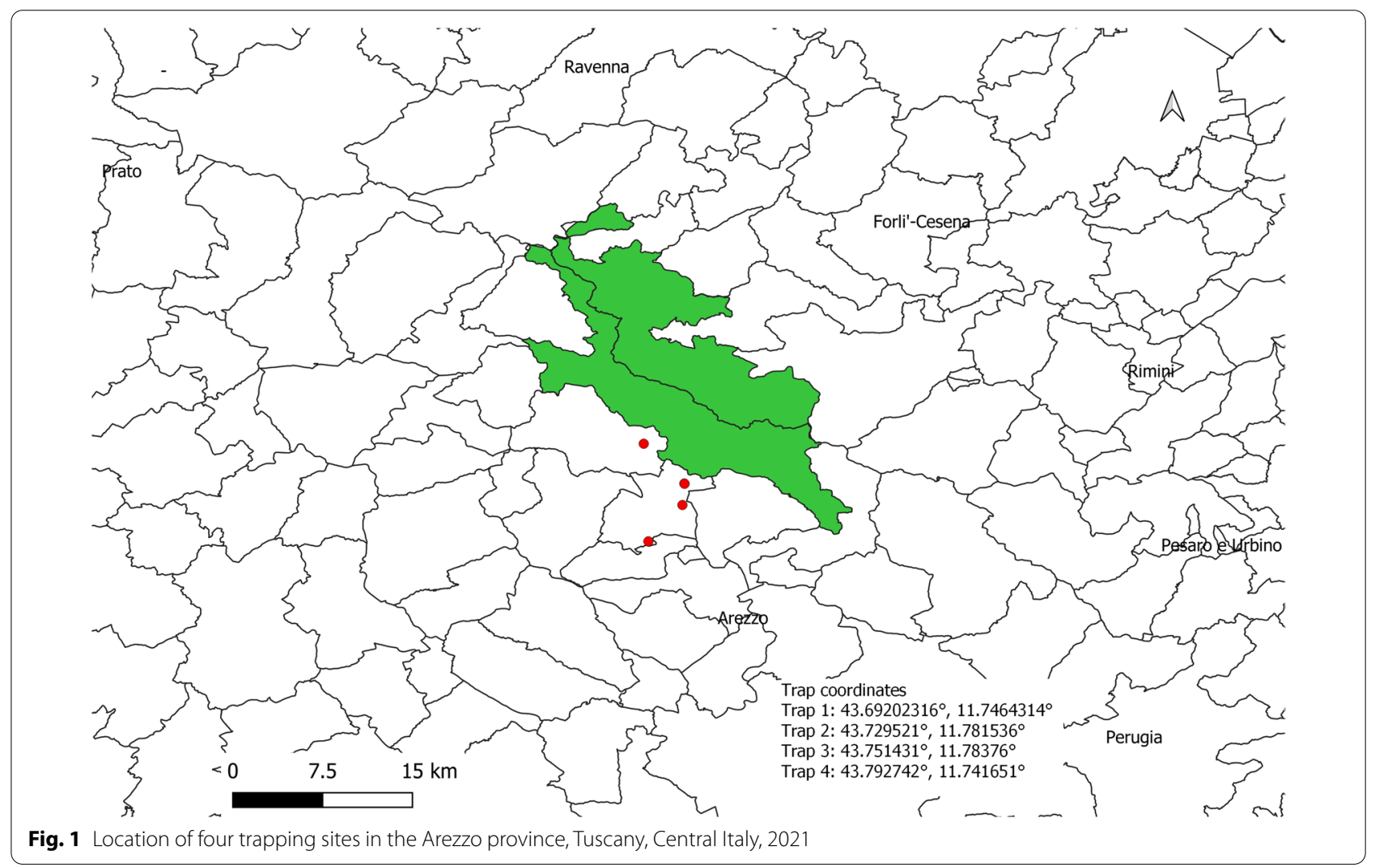


Table 1 Parasitic load in Baylisascaris procyonis-positive raccoons

\begin{tabular}{lll}
\hline $\begin{array}{l}\text { B. procyonis-positive } \\
\text { raccoons }\end{array}$ & $\begin{array}{l}\text { Number of adult parasites } \\
\text { (range) }\end{array}$ & $\begin{array}{l}\text { Presence of } \\
\text { intestinal } \\
\text { obstruction }\end{array}$ \\
\hline 1 & $1-10$ & No \\
2 & $1-10$ & No \\
3 & $20-30$ & No \\
4 & $1-10$ & No \\
5 & $30-40$ & No \\
6 & $>100$ & Yes \\
7 & $>100$ & Yes \\
\hline
\end{tabular}

Table 2 Selected features and respective metrics of Baylisascaris procyonis

\begin{tabular}{lll}
\hline Features of B. procyonis & Measure & References \\
\hline Adult female length & $20-22 \mathrm{~cm}$ & {$[5,25]$} \\
& $20 \mathrm{~cm}$ & {$[26]$} \\
Adult male length & $9-11 \mathrm{~cm}$ & {$[5,25]$} \\
& $9 \mathrm{~cm}$ & {$[26]$} \\
Male spicules & Usually $<1 \mathrm{~mm}$ & {$[26]$} \\
Eggs & Average: $68-76 \times 55-61 \mu \mathrm{m}$ & {$[5]$} \\
& Average: $65-79 \mu \mathrm{m}$ & {$[26]$} \\
& Range: $63-88 \times 50-70 \mu \mathrm{m}$ & {$[4,25]$} \\
\hline
\end{tabular}

tan-colored, with evident black alimentary tract (Additional file 1: Figure S1, Additional file 2: Figure S2). Microscopically, characteristic features were identified (Fig. 2), such as the presence of cervical alae with cuticular bars and a pericloacal area rugosa in the males; dorsal and subventral labial papillae distinctly double; stout, uniform spicules and discrete precloacal and postcloacal groups of papillae on the tail in males [5].

Identification was confirmed by molecular methods, using a next-generation sequencing (NGS)-based amplicon sequencing approach. Small pieces (approximately one centimeter) of seven ascariid parasites harbored by the positive necropsied raccoons (one parasite for each animal) were completely lysed, following a lysis step with proteinase K. Then, total DNA was extracted using the DNeasy Blood \& Tissue Kit (Qiagen, Hilden, Germany), using the manufacturer's protocol. Amplicon sequencing targeting the internal transcribed spacer 2 (ITS-2) rDNA locus was performed on the Illumina MiSeq platform, using primers and protocols reported on the Nemabiome website (https://www.nemabiome.ca/) and previously described by Avramenko et al. [15], with slight modifications. Raw reads were cleaned by using Cutadapt version 3.4 [16], which finds and removes adapter sequences, primers, poly-A tails, and other types of unwanted sequences. The obtained reads were then analyzed by using the DADA2 $\mathrm{R}$ package version 1.12.1 [17], that implements a complete

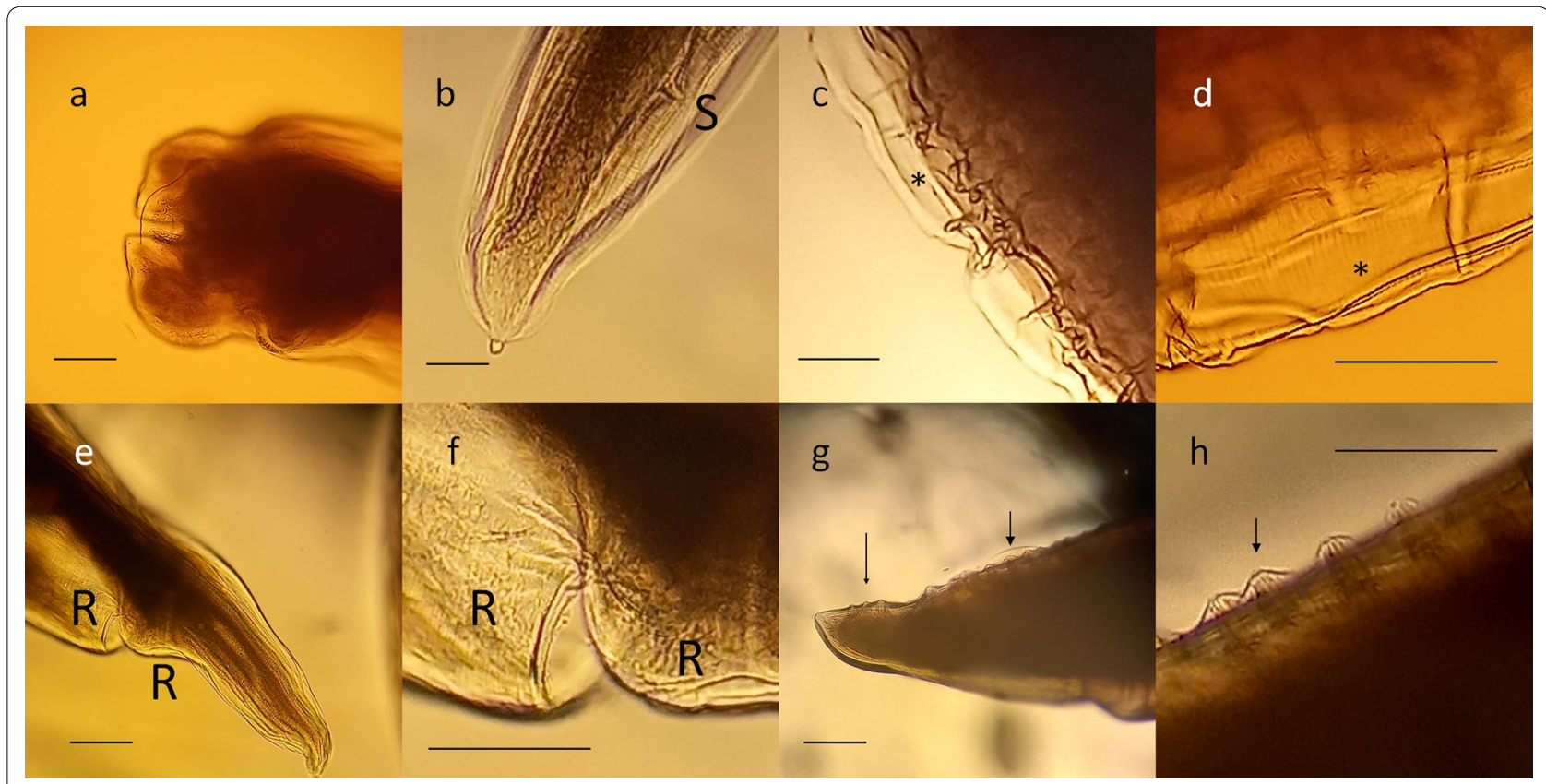

Fig. 2 Morphological details of Baylisascaris procyonis adult male. a Dorsal and subventral labial papillae. b Spike-shaped posterior end of the tail and spicule (S). c, d Cervical alae $\left(^{*}\right)$ with cuticular bars. e, f Pericloacal roughened patches (R). $\mathbf{g}$ Precloacal (large arrow) and postcloacal groups (thin arrow) of papillae. $\mathbf{h}$ Precloacal (large arrow) papillae. Scale bar: $10 \mu \mathrm{m}$ 
pipeline to turn paired-end fastq files from the sequencer into merged, denoised, chimera-free, inferred sample sequences. A $340 \mathrm{bp}$ amplicon was obtained for all the seven samples and compared by BLAST analysis with publicly available databases, such as GenBank and the Nemabiome curated database. One of the obtained sequences was submitted to the European Nucleotide Archive (http:// www.ebi.ac.uk/ena) under accession number ERZ4009650. One hundred percent coverage and identity with a B. procyonis sequence deposited in GenBank (accession number: MZ092853.1) was obtained for all seven samples.

Previous investigations on the parasitic fauna of raccoons in Italy did not highlight the presence of B. procyonis in the reproductive population set in Northern Italy [18], thus our study represents the first report of this parasite from Italy. Besides being the report of an alien species from a new country, this finding is worthy of being reported due to the potential sanitary relevance of this parasite for humans. All the infected raccoons originated from the same area of Casentino valley, Arezzo, Tuscany (Central Italy). The finding of this parasite in seven out of the 21 raccoons necropsied at present (33.3\% prevalence) possibly suggests a high prevalence in the free-ranging population settled in Tuscany, with a transmission risk to people, wildlife, and domestic species [19]. This parasitosis could indeed affect both public health and native wildlife species susceptible to the transmission of the infection, since the raccoon population is settled near a national protected area, the Foreste Casentinesi, Monte Falterona e Campigna National Park.

Health risks associated with the introduction or translocation of alien vertebrate species into a new geographic area are well known. The vertebrate hosts have to be regarded as potential carriers of macro- and microparasites, agents of both animal and zoonotic diseases. The interaction of imported pathogens with new hosts (naïve or partially adapted) has often been the cause of serious consequences for animal and public health. Examples are diseases caused by the introduction of Fascioloides magna, rabies or African horse sickness viruses, Mycobacterium bovis, or Brucella spp. into a new biocenosis [20-23].

Although the risk of acquiring baylisascariasis is highest when synanthropic populations of raccoons dwell close to human settlings, or when raccoons are kept as pets $[1,2], B$. procyonis eggs can remain infective for years in forest soil, and each infected raccoon can shed millions of eggs each day. Hence, the presence of infected raccoons in a natural area is likely to pose a public health risk [2], especially in a region like Casentino, which is geared towards ecotourism, hunting, and extensive farming. In Italy, the raccoon is regarded as an invasive species, and an eradication plan has been recently set up by official authorities [14]. The awareness of the presence in our country of its natural parasite B. procyonis should make the efforts aimed at its eradication even more stringent. The two populations of raccoon in Italy are not geographically contiguous and thus constitute two separate nuclei of different origin [18]. The Casentino raccoon population was first detected in 2013 [13], while the Lombardy population dates back to 2004. Suggested origins for the northern Italy population include dispersal from a feral raccoon population in Switzerland [12] or sporadic escapes or releases from private owners [24]. Since to the best of the authors' knowledge the Northern Italy raccoon population is currently $B$. procyonis-free, every effort should be undertaken to avoid the merging of the two Italian reproductive populations, in order to prevent a further spread of this zoonotic parasite.

\section{Supplementary Information}

The online version contains supplementary material available at https://doi. org/10.1186/s13071-021-05116-3.

Additional file 1: Figure S1. Numerous adults of Baylisascaris procyonis in the small intestine of an infected raccoon.

Additional file 2: Figure S2. Two female (top) and one male adults of Baylisascaris procyonis.

Acknowledgements

The authors wish to thank Dr. Ziad Mezher for the map of cage-trapping sites.

Authors' contributions

Conceptualization, $A L, G F$, and $A M$; methodology, $A L, A B$, and $C D L$; investigation, $A L, G B, C D, E L D, V C, N C$, and $L M$; writing-original draft preparation, $A L$, $\mathrm{GF}, \mathrm{AM}, \mathrm{AB}$, and $\mathrm{CDL}$; writing - review and editing, $\mathrm{AL}, \mathrm{GB}, \mathrm{CD}, \mathrm{GF}, \mathrm{AM}, \mathrm{ELD}, \mathrm{VC}$, $A B, N C, L M$, and CDL. All authors have read and approved the final manuscript.

Funding

This research received no external funding.

Availability of data and materials

One of the sequences obtained in this study is publicly available on the European Nucleotide Archive (ENA) under the accession number ERZ4009650. All other data generated or analyzed during this study are included in this published article.

\section{Declarations}

Ethics approval and consent to participate Not applicable.

Consent for publication

Not applicable.

Competing interests

The authors declare that they have no competing interests.

Author details

'Istituto Zooprofilattico Sperimentale del Lazio e Della Toscana "M. Aleandri", Arezzo, Italy. ${ }^{2}$ Istituto Zooprofilattico Sperimentale del Lazio e Della Toscana "M. Aleandri", Grosseto, Italy. ${ }^{3}$ Istituto Zooprofilattico Sperimentale del Lazio e Della Toscana "M. Aleandri", Rome, Italy. ${ }^{4}$ Parco Nazionale Foreste Casentinesi, Monte Falterona e Campigna, Arezzo, Italy. ${ }^{5}$ Regione Toscana, Arezzo, Italy. 
Received: 16 September 2021 Accepted: 4 December 2021

Published online: 12 January 2022

\section{References}

1. Sorvillo F, Ash LR, Berlin OGW, Yatabe J, Degiorgio C, Morse SA. Baylisascaris procyonis: an emerging helminthic zoonosis. Emerg Infect Dis. 2002;8:355-9

2. Graeff-Teixeira C, Morassutti AL, Kazacos KR. Update on baylisascariasis, a highly pathogenic zoonotic infection. Clin Microbiol Rev. 2016;29:375-99.

3. Page K, Beasley JC, Olson ZH, Smyser TJ, Downey M, Kellner KF, et al. Reducing Baylisascaris procyonis roundworm larvae in raccoon latrines. Emerg Infect Dis. 2011;17:90-3.

4. Kazacos KR, Jelicks LA, Tanowitz HB. Baylisascaris larva migrans. In: Garcia HH, Tanowitz HB, Del Brutto OH, editors. Handbook of clinical neurology. 1st ed. Elsevier B.V:: Amsterdam; 2013. p. 251-62.

5. Kazacos KR. Baylisascaris procyonis and related species. In: Samuel WM, Pybus MJ, Kocan AA, editors. Parasitic diseases of wild mammals. 2nd ed. lowa State University Press; 2008. p. 301-41.

6. Al-Sabi MNS, Chriél M, Hansen MS, Enemark HL. Baylisascaris procyonis in wild raccoons (Procyon lotor) in Denmark. Vet Parasitol Reg Stud Rep. 2015;1-2:55-8.

7. Duscher GG, Frantz AC, Kuebber-Heiss A, Fuehrer HP, Heddergott M. A potential zoonotic threat: first detection of Baylisascaris procyonis in a wild raccoon from Austria. Transbound Emerg Dis. 2020. https://doi.org/ 10.1111/tbed.13963.

8. Karamon J, Kochanowski M, Cencek T, Bartoszewicz M, Kusyk P. Gastrointestinal helminths of raccoons (Procyon lotor) in western Poland (Lubuskie province), with particular regard to Baylisascaris procyonis. Bull Vet Inst Pulawy. 2014;58:547-52.

9. Rentería-Solís Z, Birka S, Schmäschke R, Król N, Obiegala A. First detection of Baylisascaris procyonis in wild raccoons (Procyon lotor) from Leipzig, Saxony, Eastern Germany. Parasitol Res. 2018;117:3289-92.

10. Küchle M, Knorr HLJ, Medenblik-Frysch S, Weber A, Bauer C, Naumann $\mathrm{GOH}$. Diffuse unilateral subacute neuroretinitis syndrome in a German most likely caused by the raccoon roundworm, Baylisascaris procyonis. Graefe's Arch Clin Exp Ophthalmol. 1993;231:48-51.

11. Schwarz S, Sutor A, Mattis R, Conraths FJ. Der waschbärspulwurm (Baylisascaris procyonis) - Kein zoonoserisiko für Brandenburg? Berl Munch Tierarztl Wochenschr. 2015;128:34-8.

12. Canova L, Rossi S. First records of the northern raccoon Procyon Lotor in Italy. Hystrix. 2008;19:179-82.

13. Boscherini A, Mazza G, Menchetti M, Laurenzi A, Mori E. Time is running out! Rapid range expansion of the invasive northern raccoon in central Italy. Mammalia. 2019;84:98-101.

14. Panzeri M, Bisi F, Martinoli A, Franzetti B, Carnevali L. Piano nazionale di gestione del procione (Procyon lotor). 2020. https://www.minambiente.it/ sites/default/files/archivio/allegati/biodiversita/pg_procyon_lotor_2020_ def.pdf. Accessed 15 September 2021

15. Avramenko RW, Redman EM, Lewis R, Yazwinski TA, Wasmuth JD, Gilleard JS. Exploring the gastrointestinal "nemabiome" - deep amplicon sequencing to quantify the species composition of parasitic nematode communities. PLOS ONE. 2015;10:1-18.

16. Martin M. Cutadapt removes adapter sequences from high-throughput sequencing reads. EMBnet J EMBnet Stichting. 2011;17:10.

17. Callahan BJ, McMurdie PJ, Rosen MJ, Han AW, Johnson AJA, Holmes SP. DADA2: high-resolution sample inference from Illumina amplicon data. Nat Methods. 2016:13:581-3.

18. Romeo C, Cafiso A, Fesce E, Martínez-Rondán FJ, Panzeri M, Martinoli A, et al. Lost and found: helminths infecting invasive raccoons introduced to Italy. Parasitol Int. 2021;83:2020-2.

19. Hazlett M, Cai HY, Sparling S, You Q. Neurologic Baylisascaris procyonis infection in a young dog. Can Vet J. 2018;59:1325.

20. Araujo Carreira JC, Bueno C, Machado da Silva AV. Wild mammal translocations: a public health concern. Open J Anim Sci. 2020;10:64-133.

21. Daszak P, Cunningham AA, Hyatt AD. Emerging infectious diseases of wildlife - threats to biodiversity and human health. Science. 2000;287:443-9.

22. Hatcher MJ, Dick JTA, Dunn AM. Disease emergence and invasions. Funct Ecol. 2012;26:1275-87.
23. Chinchio E, Crotta M, Romeo C, Drewe JA, Guitian J, Ferrari N. Invasive alien species and disease risk: an open challenge in public and animal health. PLoS Pathog. 2020;16:1-7.

24. Mori E, Mazza G, Menchetti M, Panzeri M, Gager Y, Bertolino S, et al. The masked invader strikes again: the conquest of Italy by the Northern raccoon. Hystrix. 2015;26:1-5.

25. Gavin PJ, Kazacos KR, Shulman ST. Baylisascariasis. Clin Microbiol Rev. 2005. https://doi.org/10.1128/CMR.18.4.703-718.2005.

26. Sprent JFA. Notes on Ascaris and Toxascaris, with a definition of Baylisascaris gen.nov. Parasitology. 1968;58:185-98.

\section{Publisher's Note}

Springer Nature remains neutral with regard to jurisdictional claims in published maps and institutional affiliations.

Ready to submit your research? Choose BMC and benefit from:

- fast, convenient online submission

- thorough peer review by experienced researchers in your field

- rapid publication on acceptance

- support for research data, including large and complex data types

- gold Open Access which fosters wider collaboration and increased citations

- maximum visibility for your research: over $100 \mathrm{M}$ website views per year

At BMC, research is always in progress.

Learn more biomedcentral.com/submissions 